\section{Effect of Teaching Recommended World Health Organization Technique on the Use of Alcohol-Based Hand Rub by Medical Students}

Nosocomial infections affect up to $10 \%$ of hospitalized patients, resulting in prolonged hospital stays, substantial morbidity and mortality, and excessive costs. ${ }^{1}$ Hand hygiene is a key component in the prevention of nosocomial infections. ${ }^{2,3,4}$ Its goal is a sufficient reduction of microbial counts on the skin to prevent cross-transmission of pathogens between patients. $^{5}$

Physicians, in particular, have the lowest rate of adherence to hand hygiene, compared with other staff groups. ${ }^{6,7}$ Recently, we documented a significant improvement in the level of bacterial killing by teaching the technique recommended by the World Health Organization (WHO) ${ }^{8}$ to a large group of nurses; however, data on the effect of such a training program for physicians are lacking. To our knowledge, no study so far has examined the effect of teaching the WHOrecommended technique for use of alcohol-based hand rub (ABHR) among medical students. The aim of this study was to evaluate the level of bacterial killing on hands of medical students using the WHO technique. In addition, we hypothesized that advanced medical students improve in hygiene performance because they receive multiple training sessions while on clinical duty.

Medical students from academic years 1 through 4 at the University of Basel, Switzerland, studying during the time period from October 2001 through April 2009, attended a training lecture on the scientific background on hand hygiene that was based on the guideline issued by the WHO. ${ }^{8}$ The 6 steps of proper hand hygiene technique described in the WHO guideline ${ }^{8}$ were demonstrated by providing an on-site presentation by an infection control professional and making recommendations for improvement after the students passed visual evaluation. This visual evaluation consisted of testing the technique by the addition of a fluorescent dye to the ABHR (2-propanol, $45.0 \mathrm{~g}$; 1-propanol, $30.0 \mathrm{~g}$; and mecetronium ethylsulfate $0.2 \mathrm{~g}$ ) (Sterillium; Bode). After the hand hygiene procedure, students placed their hands in a standardized box under UV light; the areas of the hand that had been missed by the hand rub did not fluoresce. Compliance with recommended WHO technique was continuously monitored by at least 2 infection control professionals.

The number of colony-forming units (CFUs) of bacteria on the fingertips was determined before and after use of ABHR by the finger imprint technique. This is done by ob- taining an imprint of the 5 fingertips of the dominant hand on a culture plate and subsequently quantifying bacterial growth as CFUs per plate, as described elsewhere. ${ }^{10}$

Data were transferred to a database (Microsoft Excel 2007) and cross-checked for errors before being exported to statistical software (SPSS, version 15.0). Categorical data were compared using the $\chi^{2}$ test or Fisher exact test, as appropriate.

From 2001 to 2009 , we enrolled 563 medical students from academic years 1 through 4; of these, 257 students were in academic years 1 and 2 and 306 students were in academic years 3 and 4. Before the use of ABHR, the bacterial density on the hands of students was 26-100 CFUs per plate for 259 students (46\%) and was more than 100 CFUs per plate for 207 students (36.8\%). Fewer than 26 CFUs per plate were found for the remaining 97 students (17.2\%). Staphylococcus aureus was recovered from the hands of 68 students $(12.1 \%)$ before use of ABHR. Gram-negative bacteria (Klebsiella pneumoniae) were recovered from the hand of 1 student $(0.2 \%)$. The skin flora found on the hands of the medical students before use of ABHR were Propionibacterium species, Corynebacterium species, coagulase-negative staphylococci, and Bacillus species.

After the use of ABHR, 244 medical students (43.3\%) had no detectable bacteria on their hands, $262(46.5 \%)$ had very low bacterial density (fewer than 25 CFUs per plate), 45 (8\%) had 25-100 CFUs per plate, and $12(2.1 \%)$ had fewer than 100 CFUs per plate. The difference in the density of CFUs before and after the use of ABHR was highly significant $(P<.001)$. S. aureus was eliminated from the hands of $98.9 \%$ of students after applying the ABHR according to the WHO technique; this was a statistically highly significant reduction.

There was no significant difference in baseline bacterial density between students in academic years 1 and 2 and students in academic years 3 and 4. After use of ABHR, however, students in academic years 3 and 4 achieved a significantly greater reduction in bacterial density on their hands than did the medical students in academic years 1 and $2(P<.001)$ (Table 1).

Use of WHO-recommended technique to apply ABHR,

TABLE 1. Presence of Bacteria on the Hands of Medical Students after the Use of Alcohol-Based Hand Rub, According to Academic Year

\begin{tabular}{lccc}
\hline & \multicolumn{3}{c}{ No. (\%) of students } \\
\cline { 2 - 4 } & & $\begin{array}{c}\text { With no } \\
\text { bacteria } \\
\text { Academic }\end{array}$ & $\begin{array}{c}\text { With residual } \\
\text { bacteria } \\
\text { detected }\end{array}$ \\
\hline year group & Overall & $89(35)$ & $168(65)$ \\
Years 1 and 2 & 257 & $155(51)$ & $151(49)$ \\
\hline
\end{tabular}

${ }^{2} P<.001$ for comparison of students from academic years 3 and 4 and students from academic years 1 and 2 . 
under supervision, achieved a high level of bacterial killing, eliminating almost all pathogens from the transient flora. Advanced medical students in academic years 3 and 4 achieved a significantly greater reduction in bacterial density on their hands than did students in the first 2 years of training. This difference in performance most likely relates to their participation in repeated training sessions promoting the WHO hand hygiene technique, which is part of their routine training at the University Medical School of Basel. This observation underlines the need for repeated training programs throughout medical school and later during professional life. Whitby et al ${ }^{11}$ also showed that interventions to improve compliance with hand hygiene among healthcare workers can be successful and that, provided intermittent reinforcement of the program is continued, this improvement can be maintained for at least 2 years after the intervention.

Structured training programs on the scientific background of hand hygiene based on the guidelines issued by $\mathrm{WHO},{ }^{8}$ as well as on the proper technique for use of ABHR, should be included in the curriculum of medical students. Furthermore, repeated training programs should be offered to physicians throughout professional life.

\section{ACKNOWLEDGMENTS}

Potential conflicts of interest. All authors report no conflicts of interest relevant to this article.

S. Tschudin Sutter, MD; R. Frei, MD; M. Dangel A. F. Widmer, MD, MS

From the Division of Infectious Diseases and Hospital Epidemiology (S.T.S., M.D., A.F.W.) and the Division of Clinical Microbiology (R.F.), University Hospital Basel, Basel, Switzerland.

Address reprint requests to Andreas F. Widmer, MD, MS, Division of Infectious Diseases and Hospital Epidemiology, University Hospital Basel, Petersgraben 4, CH-4031 Basel, Switzerland (widmera@uhbs.ch).

Received February 4, 2010; accepted May 3, 2010; electronically published September 23, 2010.

Presented in part: 49th Interscience Conference on Antimicrobial Agents and Chemotherapy; San Francisco, CA; September 2009.

(C) 2010 by The Society for Healthcare Epidemiology of America. All rights reserved. 0899-823X/2010/3111-0016\$15.00. DOI: 10.1086/656745

\section{REFERENCES}

1. Burke JP. Infection control-a problem for patient safety. $N$ Engl J Med 2003;348:651-656.

2. Mangram AJ, Horan TC, Pearson ML, Silver LC, Jarvis WR; Hospital Infection Control Practices Advisory Committee. Guideline for prevention of surgical site infection 1999. Infect Control Hosp Epidemiol 1999;20: 250-278.

3. O'Grady NP, Alexander M, Dellinger EP, et al. Guidelines for the prevention of intravascular catheter-related infections. MMWR Recomm Rep 2002;51:1-29.

4. Tablan OC, Anderson LJ, Besser R, Bridges C, Hajjeh R; CDC; Healthcare Infection Control Practices Advisory Committee. Guidelines for preventing health-care-associated pneumonia, 2003: recommendations of
$\mathrm{CDC}$ and the Healthcare Infection Control Practices Advisory Committee. MMWR Recomm Rep 2004;53:1-36.

5. Trampuz A, Widmer AF. Hand hygiene: a frequently missed lifesaving opportunity during patient care. Mayo Clin Proc 2004;79:109-116.

6. Lipsett PA, Swoboda SM. Handwashing compliance depends on professional status. Surg Infect (Larchmt) 2001;2:241-245.

7. Eckmanns T, Bessert J, Behnke M, Gastmeier P, Ruden H. Compliance with antseptic hand rub use in intensive care units: the Hawthorne effect. Infect Control Hosp Epidemiol 2006; 27:931-934.

8. World Health Organization (WHO). WHO guidelines for hand hygiene in health care. Geneva, Switzerland; WHO, 2009.

9. Widmer AF, Conzelmann M, Tomic M, Frei R, Stranden AM. Introducing alcohol-based hand rub for hand hygiene: the critical need for training. Infect Control Hosp Epidemiol 2007;28:50-54.

10. Pittet D, Dharan S, Touveneau S, Sauvan V, Perneger TV. Bacterial contamination of the hands of hospital staff during routine patient care. Arch Intern Med 1999;159:821-826.

11. Whitby M, McLaws ML, Slater K, Tong E, Johnson B. Three successful interventions in health care workers that improve compliance with hand hygiene: is sustained replication possible? Am I Infect Control 2008;36: 349-355.

\section{Healthcare-Associated Infection: A Significant Cause of Hospital Readmission}

Healthcare-associated infections (HAIs) cut across different services and diagnostic categories. Previous studies ${ }^{1-4}$ have not specifically addressed hospital readmissions caused by HAI. We undertook this pilot study to evaluate the proportion and characteristics of patients readmitted to the hospital due to HAI.

We performed an observational, prospective cohort study. The setting was Parkland Memorial Hospital (PMH), a 672 bed, county tax-supported, tertiary care academic referral center that provides a wide range of services, including level I trauma, burn, transplantation, and high-risk obstetrics. Patients who were readmitted to PMH within 28 days after discharge from an inpatient unit in PMH during a 3-month period from April through June 2009 were identified from the hospital administrative database. We excluded patients who had the following characteristics during the index admission: admission for 23-hour observation; neonates; patients undergoing chemotherapy, radiation therapy, rehabilitation, or hemodialysis; and patients who had died. Demographic data, such as age, discharging and readmitting service, sex, ethnicity, language, and whether the patient reported need for an interpreter were collected. Presence of HAI within 48 hours after readmission was ascertained after reviewing medical records for presence of clinical and laboratory evidence of HAI and applying definitions from the Centers for Disease Control-National Health Safety Network. ${ }^{5}$ The HAI was determined to be the primary cause of readmission if the attending physician documentation indi- 